\title{
Assessment of Environmental Health Knowledge, Attitude and Behavior among High School Students in a USA Southeast Texas School District
}

\author{
Israel G. Msengi ${ }^{*}$, Raymond Doe ${ }^{2}$ \\ ${ }^{1}$ Health and Kinesiology Department, Lamar University, Beaumont, USA \\ ${ }^{2}$ Department of Psychology, Lamar University, Beaumont, USA \\ Email: *msengig99@yahoo.com,rdoe@lamar.edu
}

How to cite this paper: Msengi, I.G. and Doe, R. (2017) Assessment of Environmental Health Knowledge, Attitude and Behavior among High School Students in a USA Southeast Texas School District. Open Journal of Preventive Medicine, 7, 247-260. https://doi.org/10.4236/ojpm.2017.712020

Received: November 1, 2017

Accepted: December 8, 2017

Published: December 11, 2017

Copyright $\odot 2017$ by authors and Scientific Research Publishing Inc. This work is licensed under the Creative Commons Attribution International License (CC BY 4.0).

http://creativecommons.org/licenses/by/4.0/

(c) (i) Open Access

\begin{abstract}
This cross-sectional descriptive study assessed general environmental health literacy among students focusing on their knowledge, skills, attitudes and behaviors regarding the environmental health, stewardship, and sustainability, using a questionnaire consisting of 35 core questions from the Centers for Diseases Control (CDCs). Students $(N=185)$ from three high schools in the district were asked through their class teachers to voluntarily complete the questionnaire. Results indicated that about $41 \%(n=77)$ of the students lacked knowledge regarding potential sources of radiation exposure and 70\% ( $n=133$ ) lacked knowledge regarding radon gas being the number one risk factor for lung cancer among non-smokers. Additionally, the ANOVA test indicated significant knowledge differences among school location. Students in school \#1, located in the most affluent area, had significantly higher knowledge scores $(M=4.39)$ than school \#2 located in a moderately affluent area $(M=3.50)$. Furthermore, we found significant differences in ethnicity on the environmental health attitude of the high school students. Black students reported lower positive environmental health attitude $(M=29.86)$ than White students $(M=32.63)$, Hispanic students $(M=32.33)$ and Asian students $(M=$ 33.84). These findings demonstrated knowledge deficiency in some key areas in environmental health particularly the environmental diseases and conditions caused by manmade hazards such as pesticides, chemicals, radiation, air, water, and soil pollution. Targeted educational interventions to increase awareness and understanding of health effects, exposure to environmental hazards and carcinogens as well as risks associated to direct exposure as in this study, radon and radiation, should be provided to high school students.
\end{abstract}


Practical education through tours where students can observe directly and participating in laboratory experiments could empower the students to translate this knowledge into positive environmental health behaviors and practices now and in the future.

\section{Keywords}

Environmental Health, High School Students, Knowledge, Attitude, Behavior, Exposure, Radon, Radiation, Recycling

\section{Introduction}

Environmental health education and sustainability practices in schools are an important educational component in the $21^{\text {st }}$ century (Hausbeck, Milbrath, and Enright, 1992) [1]. However little is done to educate this important group of elementary, middle, and high school students regarding environmental health issues (Bradley, Wliczek, and Zajicek, 1999) [2]. The United States Department of Health and Human Services in its Healthy People 2020 objectives and goals for environmental health section EH-16 document recommends an increase in "the proportion of the Nation's elementary, middle, and high schools that have official school policies and engage in practices that promote a healthy and safe physical school environment" in the area of indoor air quality, mold problems, labeling, storing, and disposing of hazardous materials, reducing exposure to pesticides, lead issues, coliforms, and bacteria in school environments [3]. With environmental issues receiving greater attention than before, it is expected that high school students are more aware of environmental health issues today than ever before (Gambro \& Switzky, 1994) [4]. Over years now, there has been a call from various organizations such as schools, local communities, and private sectors to incorporate environmental education in the K-12 curriculum (De Lavega, 2004) [5]. Majority of the current school programs rely on a series of environmental activities which are incorporated into any course within and existing curriculum (DeLavega, 2004; Naquin, Cole, Bowers \& Walkwitz, 2011) [5] [6]. The Texas Essential Knowledge and Skills (TEKS) require an incorporation of environmental designs in the curriculum so that high school students are able to acquire psychological, physiological, and sociological knowledge regarding enhancement of environments in which individuals work and live [7].

With the current condition of the world today, environmental education is to a large extent essential due to declining resources and diminishing environmental quality (Green, 2015) [8]. On the other hand, growing evidence from research and environmental practices indicate that green schools can save money, improve health, and boost academic achievement (Chapman, 2012) [9].

In lieu of the United States Healthy People 2020 objectives that emphasize designing environmental educational program to develop environmental literacy among students, this study assessed general environmental health literacy among 
students focusing on their knowledge, attitudes and behaviors regarding the environmental health, stewardship, and sustainability [2].

\subsection{Theoretical Framework}

On the global stage, there has been renewed interest and focus on environmental issues, mostly with young people who are more engaged and leading the call to save the environment. Gronhoj and Thogersen (2012) argued that even though young people hold favorable environmental attitudes, they are less committed to pro-environmental behaviors which are largely influenced by their family context [10]. Understanding the interplay of environmental health knowledge, attitude and behavior of these key stakeholders currently in high schools is thus crucial if broad policies and interventions are to be implemented. Earlier, Leventhal (1973) asserted that knowledge stands out as the only drive, instigating an individual's desire to act [11]. With the Health Belief Model proposed by Rosenstock (1974), individual's environmental health behavior is determined by the individual's perception of the threat, threat severity, the value placed on the benefits from changing the behavior, barriers to changing the behavior as well as self-efficacy to change the behavior [12]. However, we all know simply rolling out objectives, goals, facts and figures into existing curriculum is not sufficient in changing patterns of behavior (Ajzen, Joyce, Sheikh \& Cote, 2011; Gifford \& Nelson, 2014; Stern 2011) [13] [14] [15]. Moreover, the theory of planned behavior (Ajzen, 1991), which explains the influences of attitudes and beliefs on behavior also acknowledges contextual factors (internal and external) that are predictors of behavior intentions [16]. Adapting the theory of planned behavior, the model of the current study (see Figure 1) shows background factors such as Knowledge, Gender, Location and Ethnicity preceding beliefs which in turn informs attitudes towards environmental health leading to intentions and subsequent behavior.

Interventions in any shape or form, must recognize, current knowledge levels as well as the contextual factors influencing the beliefs that translate into attitudes, irrespective of the facts. This study therefore assesses the environmental knowledge, attitude and behavior of high school schools.

\subsection{Research Questions}

1) What are the levels of awareness, knowledge, attitude, and behavior of high school students in environmental health issues?

2) Are there demographic differences in the levels of knowledge, attitude and behavior in environmental health issues among high school student participants?

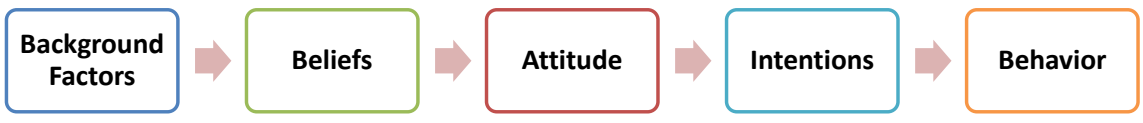

Figure 1. Adapted theory of planned behavior model depicting immediate antecedents of environmental health behavior. 


\section{Methods}

This quantitative cross-sectional descriptive study was conducted to assess high school students' knowledge, attitude and behavior regarding environmental health after obtaining an approval from the University's Institutional Review Board.

\subsection{Sample}

Participants in this study consisted of 185 high school students in a south-eastern Texas school district with a population of 5040 high school students. The sample size of 185 was determined appropriate to yield significant results with a $95 \%$ confidence level and a 7\% margin of error. All high schools in the school district were included in the study. A convenience sampling strategy (Sedgwick, 2013) with a captive audience approach was utilized to draw participants into the study [17]. Only participants who voluntarily consented verbally to participate were given the questionnaire. Participants from freshmen to senior high school levels qualified to participate in the study.

\subsection{Instrument}

The instrument utilized to collect data for this study consisted of demographic questions and core question aspects from the United States Centers for Disease Control (CDC) and has been utilized in previous studies (Ratnapradipa, Rhodes, \& Brown, 2011 and Ratnapradipa, Brown, Middleton, et al., 2011) [18] [19]. The instrument consisted of items designed to measure knowledge, attitude, and behaviors of high school students in order to gauge their understanding of environmental health issues at their academic levels. Also, the questionnaire was divided into subcategories namely Knowledge, Attitude, and Behaviors. The knowledge category consisted of 7 true and false questions, while the attitude category consisted of 12 Likert-type questions ranging from 1 (strongly disagree) to 4 (strongly agree) and there were 16 Likert-type questions for the behaviors category. The instrument was tested for internal consistence utilizing the Cronbach alpha test for the Likert-type items (attitude and behavior). All these items assessed the underlying concept of environmental attitude and behavior which is largely continuous. A higher score indicates positive environmental attitude and behavior and there is some indication that the intervals between the response ranks are approximately equal. The distribution of the scores also approach normality. The internal consistency of the total scale and subscales were also determined using Cronbach's alpha. Usually, a Cronbach's alpha of 0.70 or above is deemed acceptable (Leary, 2004) [20]. The results showed the scale to be reliable (28 items; $\alpha=0.714$ ) with the environmental health behavior subscale (16 items; $\alpha=0.705)$ being more reliable than the environmental health attitude subscale (12 items; 0.574 ). The summated scores for each sub scale were used for further analysis. 


\subsection{Data Collection}

After the approval from Institutional Review Board was obtained a student researcher was asked to contact various teachers of the high schools in the Southeastern Texas school district and seek approval to come and deliver questionnaires. These high schools are located in a city with an estimated population of 118,129 (United States Census Bureau, 2015) [21]. School \#1 is located in the western side of the city. School \#2 is located at middle of the city while school \#3 is located on the eastern part of the city. The most affluent population of the city is located on the western side. The relatively affluence population is at the center of the city; followed by the less affluent population located on eastern and southern side of the city. The researcher explained the purpose of the study and the procedure of collecting the data. The teachers took in the questionnaires and distributed them to students in their classroom who consented to participate in the survey. Before questionnaires were distributed in the classroom the researcher explained the purpose of the study and also informed students that it was voluntary to complete the questionnaire. The questionnaire took approximately 10 minutes to complete. Data collection completed within one week.

\subsection{GIS/GPS Application}

According to Kurland and Gorr (2009), GIS offers a digital management of data sources to characterize research participants and the environment in which they live [22]. These data are represented in different layers (points, lines, polygons). In this study, GIS data included the schools' layer or point data that geographically referenced the school location in which participants' average questionnaire responses are linked (i.e. point layer), lines layer (i.e. district's city boundaries), and the participants characteristics (i.e. knowledge, behaviour and attitude). This study also utilized spatial data (such as polygon data for city administrative boundaries) obtained from the city's interactive maps and GIS download website [23]. The data sets (point data) for schools were collected by the researchers using the GPS Trimble GeoXH handheld data collector. Using GIS program, mean score data for questionnaire responses per each school were added to the GIS attribute table and spatially displayed using graduated symbols in order to visually present each schools with their respective scores in each questionnaire category. This spatial data presentation revealed schools with a pattern of scores in the categories of environmental knowledge, behavior and attitude.

\subsection{Data Processing and Analysis}

The data was processed and analyzed using SPSS (version 22). The data was cleaned and screened for out of range values and outliers. Descriptive analysis was used to describe the sample. Univariate and bivariate analysis were also used to determine if there is any relationship between the demographic variables and the levels of awareness of environmental health knowledge, attitude and behavior among the high school students. 


\section{Results}

\subsection{Descriptive Analysis}

A total of 185 students from three different high schools were involved in the study. Schools involved in the study were assigned numbers (i.e., school \#1 up to \#3). Table 1 shows the distribution of their gender, ethnicity, age, classification and work status of all the students.

\subsection{Levels of Environmental Knowledge, Attitude, and Behavior of High School Students}

\subsubsection{Environmental Knowledge}

Environmental knowledge was investigated with 7 questions on solid waste disposal, sewage treatment, green house, hand washing, asthma trigger, radiation exposure and risk factor for lung cancer (see Table 2). In terms of disposing

Table 1. Demographic information.

\begin{tabular}{|c|c|c|c|c|c|c|c|c|c|c|}
\hline \multirow[t]{2}{*}{ Schools } & \multicolumn{2}{|c|}{ Gender $^{\mathrm{a}}$} & \multicolumn{2}{|c|}{ Ethnicity $^{\mathrm{a}}$} & \multicolumn{2}{|c|}{ Classification $^{\mathrm{a}}$} & \multicolumn{2}{|c|}{ Age (yrs) ${ }^{a}$} & \multicolumn{2}{|c|}{ Work Status $^{\mathrm{a}}$} \\
\hline & & Total (\%) & & Total (\%) & & Total (\%) & & Total (\%) & & Total (\%) \\
\hline \multirow{5}{*}{ School \#1 } & Male & $42(43.8)$ & White & $39(40.6)$ & Freshman & $0(0.0)$ & 14 & $0(0.0)$ & Not working & $55(57.3)$ \\
\hline & Female & $54(56.3)$ & Black & $20(20.8)$ & Sophomore & $1(1.0)$ & 15 & $1(1.0)$ & Part-time work & $40(41.7)$ \\
\hline & & & Hispanic & $8(8.3)$ & Junior & $82(85.4)$ & 16 & $22(22.9)$ & Full time work & $1(1.0)$ \\
\hline & & & Others & $6(6.3)$ & & & 18 & $10(10.4)$ & & \\
\hline & & & & & & & 19 & $0(0.0)$ & & \\
\hline \multirow{5}{*}{ School \#2 } & Male & $28(43.8)$ & White & $6(9.4)$ & Freshman & $12(19.0)$ & 14 & $3(4.7)$ & Not working & $42(65.6)$ \\
\hline & Female & $36(56.3)$ & Black & $30(46.9)$ & Sophomore & $8(12.7)$ & 15 & $9(14.1)$ & Part-time work & $21(32.8)$ \\
\hline & & & Asian & $1(1.6)$ & Senior & $13(20.6)$ & 17 & $27(42.2)$ & & \\
\hline & & & Others & $1(1.6)$ & & & 18 & $7(10.9)$ & & \\
\hline & & & & & & & 19 & $1(1.6)$ & & \\
\hline \multirow{6}{*}{ School \#3 } & Male & $8(32.0)$ & White & $6(24.0)$ & Freshman & $13(52.0)$ & 14 & $6(24.0)$ & Not working & $20(80.0)$ \\
\hline & Female & $16(64.0)$ & Black & $7(28.0)$ & Sophomore & $5(20.0)$ & 15 & $8(32.0)$ & Part-time work & $3(12.0)$ \\
\hline & & & Hispanic & $9(36.0)$ & Junior & $1(4.0)$ & 16 & $3(12.0)$ & Full time work & $2(8.0)$ \\
\hline & & & Asian & $1(4.0)$ & Senior & $6(24.0)$ & 17 & $5(20.0)$ & & \\
\hline & & & Others & $2(8.0)$ & & & 18 & $1(4.0)$ & & \\
\hline & & & & & & & 19 & $2(8.0)$ & & \\
\hline \multirow{5}{*}{ Total } & Male & $78(42.2)$ & White & $51(27.6)$ & Freshman & $25(13.5)$ & 14 & $9(4.9)$ & Not working & $117(63.2)$ \\
\hline & & & Hispanic & $43(23.2)$ & Junior & $113(61.1)$ & 16 & $36(20.5)$ & Full time work & $4(2.2)$ \\
\hline & & & Asian & $25(13.5)$ & Senior & $32(17.3)$ & 17 & $95(51.4)$ & & \\
\hline & & & Others & $9(4.9)$ & & & 18 & $18(9.7)$ & & \\
\hline & & & & & & & 19 & $3(1.6)$ & & \\
\hline
\end{tabular}

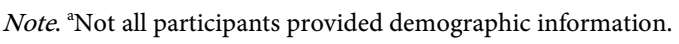


Table 2. Overall correct responses to knowledge items.

\begin{tabular}{lc}
\hline \multicolumn{1}{c}{ Environmental Knowledge Items } & $\begin{array}{c}\text { Overall Correct } \\
\text { Responses n (\%) }\end{array}$ \\
\hline The most frequent means of disposing solid waste is landfill & $97(52.4)$ \\
Improper sewage treatment can cause diseases outbreak & $147(79.5)$ \\
$\begin{array}{l}\text { Car exhaust contribute to greenhouse gas effects } \\
\text { The easiest and most effective way to avoid becoming ill is } \\
\text { frequent hand washing with soap and water } \\
\begin{array}{l}\text { Trigger for asthma can be cockroach infestation, mold and } \\
\text { second hand smoking }\end{array}\end{array}$ & $117(63.2)$ \\
$\begin{array}{l}\text { Potential source of radiation exposure include TV and computer, } \\
\text { ultraviolet light, and smoke detectors }\end{array}$ & $142(76.8)$ \\
The number one risk factor for lung cancer among non-smokers is Radon & $77(48.6)$ \\
\hline
\end{tabular}

solid waste, about $52 \%(n=97)$ of the high school students reported knowledge of the use of landfill for solid waste disposal compared to $36 \%(n=67)$ of the students who do not know that. Secondly, majority $(79 \%, n=147)$ of the students know that improper sewage treatment can cause disease outbreak. In addition, the students know about hand washing $(76 \%, \mathrm{n}=142)$ and trigger for asthma $(68 \%, n=127)$. However, about $41 \%(n=77)$ of the high school students reported no knowledge of potential sources of radiation exposure and $16 \%(\mathrm{n}=$ 30 ) of the students thought it is false that they could get radiation exposure from $\mathrm{TV}$, computer, ultraviolent light and smoke detectors. In addition, out of 185 students, 133 (70\%) of the students have no knowledge that the number one risk factor for lung cancer among non-smokers is Radon.

The knowledge questions were recoded "correct" (1) and "Incorrect" (0) to get the total knowledge score which ranged from 0 to $7(M=4.0, S D=1.51)$. No significant differences were found between Males and Females, Ethnicity, and whether or not the high school students were working or not. There was however a significant yet weak correlation between age of the high school students and their total knowledge score $(r=0.222, p=.002)$. In terms of Location of the high schools, there was a significant difference $\left(F(2,182)=7.628, p=.001, \eta_{p}^{2}=\right.$ 0.077. A post-hoc analysis using Tukey shows that high school students in School \#1 $(M=4.39, S D=1.25)$ had significantly higher total knowledge scores than School \#2 $(M=3.50, S D=1.76)$.

\subsubsection{Environmental Health Attitude and Behavior}

The environmental health attitude of the high students ranged from 14 to 41 with an average score of 31.90 ( $\mathrm{SD}=4.41$ ). Secondly, environmental health behavior scores of the students ranged from 0 to 64 with an average score of 39.23 $(\mathrm{SD}=6.67)$.

\subsection{Differences in Environmental Attitude and Behavior of High School Students}

In terms of gender of the high school students, no significant differences were found between environmental health Attitudes of males $(M=31.39, S D=4.4)$ 
and females $(M=32.34, S D=4.2) ; t(182)=1.45, p=0.148$. There was also no significant differences found between environmental health behavior of males $(M=38.59, S D=6.3)$ and females $(M=39.74, S D=6.9) ; t(182)=1.167, p=$ 0.245 .

Other demographic variables were also tested for differences. There were no significant differences found for Age, Classification, and Work status. Significant differences were however found for location of the high school and ethnicity on environmental health attitude but not environmental health behavior. A one-way Analysis of Variance (ANOVA) results showed an overall significant difference in location on environmental health attitudes of high school students $\left(F(2,182)=4.97, p=.008, \eta_{p}^{2}=0.052\right.$. Post hoc analysis using Tukey showed that students in school \#1 $(M=32.61, S D=3.25)$ had higher positive environmental health attitudes than students in school \#2 $(M=30.52, S D=5.37)$. No other comparisons were statistically significant.

In addition, ANOVA results also showed an overall significant differences in ethnicity on environmental health attitude of high school students $(F(4,180)=$ 5.33, $p=0.000, \eta_{p}^{2}=.106$. Post hoc analysis using Tukey showed that Black students $(M=29.86, S D=4.85)$ had significantly lower positive environmental health attitude than White students $(M=32.63, S D=3.59$, Hispanic students $(M$ $=32.33, S D=4.47)$, and Asian students $(M=33.84, S D=3.14)$. No other comparisons were statistically significant. The preceding results above showed a trend by location and ethnicity of the high school students. Table 3 shows the cross tabulation of these two variables.

Since location and ethnicity of the high school students were the only significant results concerning their environmental health attitudes, the researchers explored these results further by looking at the association between these two variables in the population. A chi-square test of independence shows a significant relationship between location and ethnicity of the high school students, $\chi^{2}(8, N$ $=185)=60.02, p<0.001$. Further analysis was thus performed to help us understand these relationships by focusing on the ethnicity within the location of the specific high schools of interest (School \#1 and School \#2). School \#3 had too few respondents for any meaningful comparison. Within School \#1, ANOVA results showed significant differences in ethnicity on the environmental health

Table 3. Frequency distribution of student ethnicity and school location

\begin{tabular}{cccc}
\hline \multirow{2}{*}{ Ethnicity } & \multicolumn{3}{c}{ School Location } \\
\cline { 2 - 4 } & School \#1 & School \#2 & School \#3 \\
\hline White & 39 & 6 & 6 \\
Black & 20 & 30 & 7 \\
Hispanic & 8 & 26 & 9 \\
Asian & 23 & 1 & 1 \\
Other & 6 & 1 & 2 \\
\hline
\end{tabular}


attitude of the high school students $\left(F(4,91)=3.027, p=0.022, \eta_{p}^{2}=0.117\right.$. Post hoc analysis using Tukey showed that within school \#1 location, Blacks $(M$ $=30.90, S D=3.02$ ) had significantly lower positive environmental health attitude than Asian students $(M=34.17, S D=3.35)$ and no other comparisons were statistically significant. However, within school \#2 location, there were no overall significant differences in Ethnicity. This finding could be attributed to fewer ethnic groups represented in school \#2's location as can be seen in Table 3. Majority of the students in school \#2 were either Hispanics or Blacks. An analysis of the two dominant ethnic groups in school \#2 thus showed that blacks had significantly lower positive environmental health attitudes than Hispanics students $(t(54)=-2.184, p=.033)$. This ethnicity related differences may just be within school location since full comparison across all the three high schools was not feasible.

GIS/GPS was applied to augment this study. GIS data points on the location of the High Schools were collected and post processed in order to spatially display school location and the related mean scores on environmental knowledge, attitude, and behavior (see Figure 2). Similar to the already reported findings in this study, the spatial display show the high school located on the western side of the city (school \#1) had relatively higher mean scores in all three categories of the surveyed environmental components (knowledge, attitude, and behavior).

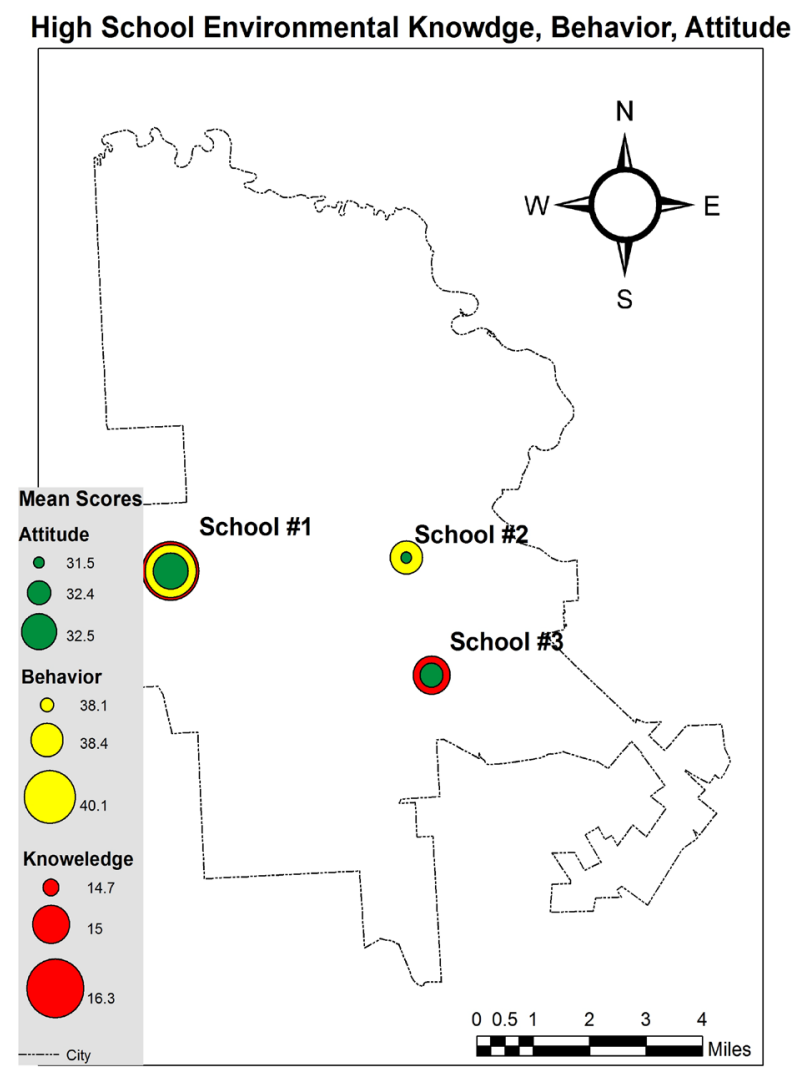

Figure 2. Spatial display High School location and mean scores of environmental knowledge, attitude and behavior. 


\section{Discussion}

This study assessed high school students' knowledge, attitude, and behavior regarding environmental health. A total of 185 high school students from three different high schools in a South Eastern Texas school district were as to voluntarily respond to a questionnaire that gauged the knowledge level, attitude and behaviors on environment health. The results of the environmental health knowledge assessment of the high school students showed that most of the high school students only have appreciable knowledge about environmental practices that are tangible and solid or liquid based. It is also likely that most of the students that correctly self-reported knowledge of these environmental practices have at one point interacted or experienced these practices for example hand washing, disease outbreak, and asthma. Environmental knowledge on intangible or invisible practices such as Radon gas release and radiation exposure received the lowest knowledge scores. It is also worth arguing that majority of the high school students have not seen where their solid wastes end up. With slightly above average scores in environmental health knowledge, it is fair to say that there is insufficient basic knowledge about environmental health among the high school students. Previous studies among college students (e.g., Ratnapradipa, Brown, Middleton \& Wodika, 2011) also found similar results [19]. They also argued that due to numerous studies conducted on hand washing effectiveness coupled with relentless campaigns in hospitals, public restrooms, workplaces and the media; may have contributed to knowledge of hand washing as the most effective way that one can avoid becoming ill. Similarly, with the increased focus and discussion on climate change and global warming, one would expect that high school students who are learning science related subjects would overwhelmingly (at least) agree to the item that "Car exhaust contribute to greenhouse gas effect". In this current study, about one fourth of the high school students indicated that they "don't know" to the only item on green house with an additional 9\% indicating that "Car exhaust do not contribute to greenhouse gas effect". One does not need to go far to look for answers. With the ongoing discourse on whether anthropogenic activities have increased global warming with political divides on the issue and only fueled by the media and conspirators; high schools students caught in the middle of this debacle might be a little skeptical if not doubtful. It is therefore not enough to have knowledge about the environmental health practices. As Tempte and McCall (2001) pointed out, it also depends on whether the individual perceives (internally) that these environmental practices are harmful [24]. Take Radon exposure for example, as many as 21, 000 lung cancer deaths have been caused by radon each year according to the U.S. Environmental Protection Agency (US EPA), Agency for Toxic Substances and Disease Registry [ATSDR] (2012) and the Office of Radiation and Indoor Air (2003) [25] [26] [27]. As the second leading cause for lung cancer with more than $\$ 2$ billion dollars spent in health care costs (Oster, Colditz \& Kelley, 1984); more than $70 \%$ of the high schools students in this study do not know about Radon [28]. 
On the other hand, high school students scored well on some knowledge items such as environmental triggers for asthma (68.6\%) and cause for diseases outbreak due to improper sewage treatment $(79.5 \%)$. This may have resulted from common knowledge of topic and the actual occurrences of the health conditions caused by these factors. For example, seasonal allergies and pollution which frequently tend to trigger asthma symptoms to students with this condition. Common allergens include dust mites pollen, animal dander, molds, certain food such as peanuts, second hand smoke, cockroach droppings, chemical fumes, vehicle exhaust, and particulate matter from polluted air. Similarly, with regard to sewage treatment, higher percentage true scores could be due to familiarity of the topic by high school students. Majority of students would not hesitate to immediately correlate sewage with disease outbreak because the content is filthy and undesirable to be around it.

The application of GIS in this study provided the mean to enhance and improve this study by providing a unique way to visualize and geographically analyze and display data to show which school performed better than the other. With the ability to spatially visualize school location in relation to their average scores in environmental knowledge and behavior, GIS can set need to examine population level factors related to these findings in this study. For example the geographic and spatial distribution of population and school locations can be directly related to the social and economic status of these populations.

\subsection{Limitations}

As with many environmental health studies, these responses were self-reports. Although anonymity of the students was used to encourage true responses, social desirability could not be eliminated and no additional information was used to verify the accuracy of these responses especially the behavioral responses. Students also self-selected to participate in this study, so the results may not necessarily reflect the opinions of those who did not participate. Although all the three high schools in this district participated in this study, some schools and sub groups willingly participated more than others as can be seen in the descriptive results. Therefore, these results may be limited in some comparisons. Future studies could focus on getting representative numbers for all the sub groups in the current population or compare these results with other school districts in the southeastern Texas region.

\subsection{Implications and Conclusion}

With the exception of ethnicity differences in knowledge scores, the overall trend in this study has revolved around Location of the high school students and Ethnicity when it comes to environmental health attitude and knowledge (not behavior). Specifically, Blacks tended to self-report lower positive environmental health attitudes than White students, Hispanics and Asian students. In addition, school \#1 which is located in predominantly affluent neighborhood reported 
higher environmental knowledge and higher positive environmental health attitude than school \#2 that is in predominantly Hispanic and Black neighborhood. While this does not attest to any causation insinuations, it is unbiased to assert that there is an environmental health knowledge gap and an environmental health attitude disparity that needs to be addressed through curriculum adjustments and addressing the source of the attitudes that are detrimental to the health of high school students. Targeted interventions such as risk awareness and direct exposure to key environmental issues (in this study, Radon exposure and radiation exposure) where students can observe directly could empower the students to translate this knowledge into positive environmental health behaviors now and in the future.

\section{References}

[1] Hausbeck, K.W., Milbrath, L.W. and Enright, S.M. (1992) Environmental Knowledge, Awareness and Concern among 11th-Grade Students: New York State. The Journal of Environmental Education, 24, 27-34. https://doi.org/10.1080/00958964.1992.9943493

[2] Bradley, J.C., Waliczek, T.M. and Zajicek, J.M. (1999) Relationship between Environmental Knowledge and Environmental Attitude of High School Students. The Journal of Environmental Education, 30, 17-21. https://doi.org/10.1080/00958969909601873

[3] United States Department of Health and Human Services (2017) Environmental Health.

https://www.healthypeople.gov/2020/topics-objectives/topic/environmental-health/ objectives

[4] Gambro, J.S. and Switzky, H.N. (1994) A National Survey of Environmental Knowledge in High School Students Levels of Knowledge and Related Variables. Distributed by ERIC Clearinghouse, Washington DC. http://www.eric.ed.gov/contentdelivery/servlet/ERICServlet?accno = ED379164

[5] De Lavega, E.L. (2004) Awareness, Knowledge, and Attitude about Environmental Education: Responses from Environmental Specialists, High School Instructors, Students, and Parents. Doctoral Dissertation, University of Central Florida Orlando, Florida.

http://stars.library.ucf.edu/cgi/viewcontent.cgi?article=1177\&context=etd

[6] Naquin, M., Cole, D., Bowers, A. and Walkwitz, E. (2011) Environmental Health Knowledge, Attitudes and Practices of Students in Grades Four through. The ICHPER-SD Journal of Research in Health, Physical Education, Recreation, Sport \& Dance, 6, 45.

[7] TEKS (2016) Chapter 122. Texas Essential Knowledge and Skills for Home Economics Education. Subchapter I. Environmental Design, High School.

http://parentresourceguide.texaschildrenscommission.gov/library_item/gov.tx.regs. admin_code_19/2259

[8] Green, K.L. (2015) Creating a Successful Environmental Education Curriculum: A Rare Example. http://hdl.handle.net/10211.3/144852

[9] Chapman, P. (2012) Environmental Education and Sustainability in U.S. Public Schools.

http://projectgreenschools.org/wp/wp-content/uploads/2014/08/USGreenSchools12 114.pdf 
[10] Gronhoj, A. and Thogersen, J. (2012) Action Speaks Louder than Words: The Effect of Personal Attitudes and Family Norms on Adolescents' Pro-Environmental Behavior. Journal of Economic Psychology, 33, 292-302. https://doi.org/10.1016/j.joep.2011.10.001

[11] Leventhal, H. (1973) Changing Attitudes and Habits to Reduce Risk Factors in Chronic Disease. American Journal of Cardiology, 31, 571-580. https://doi.org/10.1016/0002-9149(73)90324-X

[12] Rosenstock, I.M. (1974) Historical Origins of the Health Belief Model. Health Education Monographs, 2, 328-335. https://doi.org/10.1177/109019817400200403

[13] Ajzen, I., Joyce, N., Sheikh, S. and Cote, N. G. (2011) Knowledge and the Prediction of Behavior: The Role of Information Accuracy in the Theory of Planned Behavior. Basic and Applied Social Psychology, 33, 101-117. https://doi.org/10.1080/01973533.2011.568834

[14] Gifford, R. and Nilsson, A. (2014) Personal and Social Factors That Influence Pro-Environmental Concern and Behavior: A Review. International Journal of Psychology, 49, 141-157. https://doi.org/10.1002/ijop.12034

[15] Stern, P.C. (2011) Contributions of Psychology to Limiting Climate Change. American Psychologist, 66, 303-314. https://doi.org/10.1037/a0023235

[16] Ajzen, I. (1991) The Theory of Planned Behavior. Organizational and Human Decision Processes, 50, 179-211. https://doi.org/10.1016/0749-5978(91)90020-T

[17] Sedgwick, P. (2013) Convenience Sampling. BMJ, 347, f6304. https://doi.org/10.1136/bmj.f6304

[18] Ratnapradipa, D., Rhodes, D.L. and Brown, S.L. (2011) Evaluating Pre-Service Teacher Workforce: Environmental Health Knowledge, Attitude, and Behavior. Online Journal of Workforce Education and Development, 5, 1-18.

[19] Ratnapradipa, D., Brown, S.L., Middleton, W.K. and Wodika, A.B. (2011) Measuring Environmental Health Perception among College Students. The Health Educator, $43,13-20$.

[20] Leary, M.R. (2004) Introduction to Behavioral Research Methods. 4th Edition, Pearson Education, Inc., Boston.

[21] United States Census Bureau (2015) QuickFacts. http://www.census.gov/quickfacts/table/PST045215/4807000

[22] Kurland, K.S. and Gorr, W.L. (2009) GIS Tutorial for Health. 3rd Edition, ESRI Press, Redland.

[23] Beaumont Texas (2017) City Interactive Maps. http://beaumonttexas.gov/city-interactive-maps/

[24] Tempte, J.L. and McCall, J.C. (2001) Patient Attitudes towards Issues of Environmental Health. Wilderness and Environmental Medicine, 12, 92.

[25] United States Environmental Protection Agency-EPA (2013) A Citizen's Guide to Radon: The Guide to Protecting Yourself and Your Family from Radon. https://www.epa.gov/sites/production/files/2016-12/documents/2016_a_citizens_gu ide_to_radon.pdf

[26] Agency for Toxic Substances and Disease Registry (2012) Case Studies in Environmental Medicine (CSEM): Radon Toxicity. https://www.atsdr.cdc.gov/csem/radon/radon.pdf

[27] Office of Radiation and Indoor Air (2003) United States Environmental Protection Agency (EPA) EPA Assessment of Risks from Radon in Homes. https://www.epa.gov/sites/production/files/2015-05/documents/402-r-03-003.pdf 
[28] Oster, G., Colditz, G.A. and Kelly, N.L. (1984) The Economic Costs of Smoking and Benefits of Quitting for Individual Smokers. Preventive Medicine, 13, 377-389. https://doi.org/10.1016/0091-7435(84)90029-X 